\title{
SURFING THE COMPLEX INTERACTION BETWEEN NEW TECHNOLOGY AND NORMS: A RESISTANCE OR RESILIENCE ISSUE? INSIGHTS BY THE VIABLE SYSTEM APPROACH (VSA)
}

\author{
Author(s) / Auteur(s) : \\ Sergio BARILE \\ Full Professor of Business Management \\ Department of Management, Economics Faculty \\ Sapienza University of Rome (Italy) \\ Founder of ASVSA, Association for research on Viable Systems, www.asvsa.org. \\ sergio.barile@uniromal.it
}

Cristina SIMONE (corresponding author)

Associate Professor of Business Management

Department of Management, Economics Faculty

Sapienza University of Rome (Italy)

cristina.simone@uniromal.it

\author{
Antonio LA SALA \\ Research Fellow in Business Management \\ Department of Management \\ Sapienza University of Rome (Italy) \\ antonio.lasala@uniromal.it \\ Marcelo Enrique CONTI \\ Associate Professor of Environmental Management \\ Department of Management, Economics Faculty \\ Sapienza University of Rome (Italy) \\ marcelo.conti@uniroma1.it
}

\begin{abstract}
Résumé :
The paper investigates the complex interaction between technological innovation and norms: a crucial dynamic to facing the severe challenges of the Anthropocene.

On the one hand, the sedimentation of norms acts as the genetic memory of a society. Allowing a reduction in the uncertainty of human condition and ensuring greater predictability of human interaction, the set of norms tend to activate a system of constraints that normalize and legitimate technological innovations.

On the other hand, technological innovation is one of the most unpredictable and non-linear sources of change. It demands legitimization for what in the past were excluded or prohibited a priori (e.g. behaviors, ethics): this may trigger a "decoupling" process from the extant set of norms. Nevertheless, what decoupling should be legitimized? A wicked problem arises, and forking paths emerge in the socio-economic landscape.

Leading the tension between new technology (source of unpredictability) and the taken-for-granted norms (source of predictability) is crucial if the aim is to linking effectiveness and efficiency to viable sustainability. While the (still dominant) cartesian approach considers norms and new technology as separate elements of the social system, system thinking enlightens the interaction between them. This helps to unveil hidden options/feedbacks in the decoupling-recoupling process between technological innovation and the evolution of norms enriching the information variety of the decision-makers (policy makers, citizens, urban planners, etc.).

The dynamics that govern this dyad, however, are not linear: norms, in fact, do not have the same reactivity to absorb (recouple) the change triggered by new technologies (decoupling from the extant set of norms).

Although the relevance of the issue, it has been often neglected, or at least not taken in the right consideration. Therefore, aiming to investigate this dyadic relationship, the paper focuses on the ambiguous role technology plays in enabling resilience: sometimes it acts as a resilience amplifier; sometimes it is a resilience inhibitor (and even a steel cage); sometimes it provokes an undesirable deviation from the taken-for-granted codified rules.
\end{abstract}


In particular, aiming to contribute in filling this gap, and rooting in the Viable System Approach (VSA), the paper investigates why and how in some cases the interaction between technological innovation and norms leads to resistance towards change or acts as a resilience amplifier in other cases.

The paper is structured as follows: after an Introduction underlying the need to understanding the increasing tension between new technology and norms, Section 2 deals with the contribution of the VSA in understanding the social systems; then, rooting in the VSA and moving from the concept of information variety, Section 3 frames the complex interplay between new technology and taken-for-granted norms as one of the most dramatic "resistance-resilience" issue of the Anthropocene era; Section 4 proposes a more comprehensive framework discussing the range "resilience-resistance-vulnerability" and presents final reflections.

Keywords / Mots-clés :

Norms, new technology, resilience, Viable System Approach (VSA), decoupling-recoupling process

\section{NEW TECHNOLOGY AND NORMS: HOW TO SURF THE COMPLEX INTERACTION?}

This paper investigates the complex interaction between new technology and norms, one of the most crucial issues to understand and govern the challenges posed by the advent of the Anthropocene. A glimpse of this centrality, for example, can be found in the relationship between the present ecological crisis (e.g. global warming, the reduction of biodiversity, the risk of the collapse of ecosystems), and the continuous tension towards socio-economic growth (West, 2017). In fact, if principles that regulate sublinear ecological systems imply slowing down their metabolism (and their resources consumption) as their scale increases, superlinear socio-economic systems are characterized by the acceleration of their metabolism (and by the increase in the resources they need to survive) as their scale increases (Adger, 2000; West, 2017). This leads to an interesting result: "to sustain open-ended growth in light of resource limitation requires continuous cycles of paradigm-shifting innovations" (West, 2017: 452). Therefore, these accelerating cycles of innovation are the key to maintain both ecological and socioeconomic systems dynamically viable, avoiding the collapse of one or the other (West, 2017).

On the other side, however, this same innovation brings hidden and unpredictable effects: consider, for example, the progressive transfer of decision-making authority from human beings to algorithms and the related risk of a digital tyranny (Harari, 2018). This twofold issue poses crucial questions about the relationship between technological innovation and norms and states the pivotal importance of norms balancing role.

On the one hand, in fact, the sedimentation of norms acts as the genetic memory of a society. Allowing a reduction in the uncertainty of human condition and ensuring greater predictability of human interaction, the set of norms tend to activate a system of constraints that normalize and legitimate technological innovations.

On the other hand, technological innovation is one of the most unpredictable and non-linear sources of change. It demands legitimization for what in the past were excluded or prohibited a priori (e.g. behaviors, ethics): this may trigger a "decoupling" process from the extant set of norms. However, what decoupling should be legitimized? A wicked problem arises and forking paths emerge in the socio-economic landscape.

Leading the tension between technological innovation (source of unpredictability) and the taken-forgranted norms (source of predictability) is crucial if the aim is to linking effectiveness and efficiency to a viable sustainability. While the (still dominant) cartesian approach considers norms and technology innovation as separate elements of the social system, system thinking enlightens the interaction between them. This helps to unveil hidden options/feedbacks in the decoupling-recoupling process between technological innovation and the evolution of norms enriching the information variety of decision-makers (policy makers, citizens, urban planners, etc.). 
The dynamics that govern this dyad, however, are not linear: norms, in fact, do not have the same reactivity to absorb (recouple) the change triggered by technological innovation (decoupling from the extant set of norms). This is not without consequences. In the presence of disruptive innovation, this lack of readiness could after result in a fall of social resilience and a consequent social collapse (Adger, 2006). These aspects have been often neglected, or at least not taken in the right consideration. Thus, aiming to study this dyadic relationship, the paper focuses on the ambiguous role technology plays in enabling resilience: sometimes it acts as a resilience amplifier; sometimes it is a resilience inhibitor (and even a steel cage); sometimes it provokes an undesirable deviation from the taken-forgranted codified rules.

In particular, rooting in the Viable System Approach (VSA), the paper investigates why and how in some cases the interaction between technological innovation and norms leads to resistance towards change or acts as a resilience amplifier in other cases.

The paper continues with the following sections: Sec. 2 deals with the contribution of the VSA in understanding social systems by the duality structure-system; then, rooting in the VSA' information variety, Sec. 3 frames the complex interplay between technological innovation and norms as one of the most dramatic "resistance-resilience" issue of the Anthropocene era; Sec. 4 presents final reflections.

\section{THE VIABLE SYSTEM APPROACH (VSA): THE DUALITY STRUCTURE-SYSTEM AS A CONTRIBUTION TO UNDERSTANDING COMPLEX SOCIAL SYSTEMS}

The Viable System Approach (VSA) is a theoretical framework for the analysis and interpretation of systems behaviors, derived from systems thinking and based on a constructivist approach. According to the VSA, (Barile and Saviano 2011a; Barile, 2008) each entity (i.e. individual, community, and organization) can be described as a viable system (VS), whose ultimate purpose is to survive within its specific context of reference.

The (VSA) can be defined as a systemic constructionist approach (Ashby, 1956, 1958; Bateson, 1972, 1979; Watzlawick, Weakland, Fisch, 1974; Maturana, Varela, Beer, 1975; Von Foerster, 1984; Watzlawick, 1984) and aims to deepen the understanding of social complex systems.

The notion of VS was introduced by Stafford Beer (1972). According to this author, a system is viable if as a system which survives, remains united and is integral, is homeostatically balanced both internally and externally and possesses mechanisms and opportunities for growth and learning, development and adaptation, which allow it to become increasingly effective within its environment (Barile, 2008). The ultimate purpose of a viable system (VS) is to survive within its context of reference; this purpose of survival characterizes all the VSs and is reflected in the change and adaptation processes of the system's components and elements that are needed to preserve its viability.

Moving from Stafford Beer's Viable System Model, the VSA proposes an updated perspective and some conceptual innovations. In particular, the VSA proposes a new frame of the VSs based on the duality "structure-system". In fact, according to the VSA, the analysis of the structural components must be integrated by the analysis of the emergent (i.e. unpredictable and non-linear) dynamics that qualify a system. In other words, the VSA identifies two main dimensions of analysis: the structural and the systemic. The structural dimension is static and considers the parts and the relationships that exist among them; the systemic dimension is emergent, dynamic and deals with the identification of the interactions while keeping into account the structural components themselves (Barile and Saviano, 2011a). In this perspective, it is the dynamic behavior that allows the VS to learn, adapt and develop over time (principle of homeostasis) (Von Bertalanffy, 1968; Beer, 1972; Barile, 2008; Simone et al., 2018). In fact, the ultimate purpose of survival that characterizes all the VSs is reflected in the change and adaptation processes of the system's components and elements that are needed in order to preserve its viability. These conceptualizations are crucial with particular reference to change and adaptation processes; in fact, understanding how viable complex systems react to the internal and external 
solicitations by modifying their structure can be useful to analyze which are the elements that persist within new configurations and which are the ones that mutate.

The VSA holistic epistemology is becoming more relevant in a world where people are becoming more aware, unfortunately, most of the time the hard way, about the high interconnectivity of all kinds of social and natural phenomena. People need more powerful tools to think about these phenomena. These should enable them to recognize connectivity and understand the possible reverberations of their actions (Espejo, 1990).

\section{THE COMPLEX INTERACTION BETWEEN NEW TECHNOLOGY AND NORMS: A RESISTANCE OR RESILIENCE ISSUE? A VSA BASED-EXPLANATION}

\subsection{Norms, technology and the [inf $\mathrm{Vt}]$ : a structural view.}

Technology and norms are fundamental elements featuring human beings history. According to the VSA, they constitute relevant elements of the structure of the society conceived as a VS in a certain instant time $t$.

Norms are ways of behaving that are taken-for-granted and understood as natural, normal and proper (Van Maanen and Barley, 1984), and that are encoded into formal (explicit) rules or embedded in strict behavioral rules. When norms, formally or informally, delimit acceptable behaviors, they take on a structural quality. Norms provide a structural consistency for social action and encode technical, social and political knowledge that is useful for accomplishing specific goals (Elsbach, 2002). People adhere to such institutionalized norms without being explicitly aware of them and generally do not challenge them (e.g. legal services, teaching instructions, architectural practices). Deepening these theoretical aspects, norms constitute the behavioral boundaries to contain social action and permit people to discern what is allowed from what is not. According to the VSA, norms configure one of the more stable structural element of the information variety, a concept rooted in the Ashby' requisite variety $(1956,1958)$ and that expresses the overall knowledge endowment owned by a viable social system at a certain instant $t\left[\inf V_{t}\right]$ (Barile and Saviano, 2011b; Conti et al., 2019).

As the more stable element of the $\left[\inf _{t}\right]$, the taken-for-granted norms act as a genetic memory of a social system (Hayek, 1952, 1979; North, 2006). Allowing a reduction in the uncertainty of human condition and ensuring greater predictability of human interaction, the set of norms builds an implicit, pervasive order that defines the framework of the decisional process (Simon and Barnard, 1947; March, 1994). However, the taken-for-granted norms constantly face technological transformations (Van Maanen and Barley, 1984) a relevant source of change in the [infV] of a social system over time. In fact, if norms tend to frame a consistent structure of constraints that normalize technological evolution and play a role of their validation and legitimization, new technology could provoke a profound rethinking of the extant norms. Like norms, also technology represents a relevant element of the $\left[i n f V_{t}\right]$. However - for the reasons stated in the previous Section - in the emerging societies of the last decades of the Anthropocene, technology configures a less stable element (namely the more volatile one) of the [infV.].

A new technology makes possible in $t_{1}$ what until yesterday $\left(\mathrm{t}_{0}\right)$ was hardly conceivable: what about the unpredictable feedbacks emerging from the interaction between new technology and the extant set of consolidated norms? New technology demands legitimization for what in the past was excluded a priori because of its total incompatibility with the taken-for-granted norms of the extant $\left[\inf V_{t}\right]$ : it asks for the legitimization of the prohibited. However, since norms are the most stable elements of the [infV], technology and norms evolve at a different velocity. Taken-for-granted norms do not have the same reactivity to absorb (recouple) the change triggered in the $\left[i \inf V_{t}\right]$ by new technology: this different speed brings about a decoupling from technology and the extant set of norms. On the one hand, new technology changes the $\left[i n f V_{t}\right]$ available for a viable social system; on the other hand, taken-for-granted-norms could resist to this change. 
Despite the relevance of the structural view of norms and technology as a significant element of the $\left[\inf V_{t}\right]$ of a viable social system, it is not enough to appreciate how complex it is surfing between their reciprocal interaction, in particular in the (realistic) hypothesis in which they change at different speeds. For this reason, the VSA proposes a second complementary dimension - the systemic one who takes into account the $[\Delta \inf V]$ over time due to the emergence of new technology together with the eventual change of norms. This helps to understand the emerging behavior of the complex social systems: namely a behavior featured by unpredictable non-linear feedback loop.

\subsection{From structure to system: the interaction between new technology and norms}

The VSA aims to overcome a reductionist approach to the study of social issues, among which is the complex interaction between technology and norms that brings about an unpredictable change $[\Delta i n f V]$ in the $\left[\inf V_{t}\right]$.

According to the VSA, the systemic interaction between new technology and norms is a typical "resistance-resilient" issue affecting the viability of a complex social system. According to this approach, "resistance" refers to the extent to which the social system does not change the taken for granted norms -i.e. the more stable part of the $\left[\operatorname{infV}_{t}\right]$ - despite the solicitation due to the technological change (Harrison, 1979; Lake, 2013; Stark, 2014). On the other hand, "resilience" refers to the extent to which the social system can develop and transform itself by absorbing recurrent perturbations, dealing with uncertainty and risk and still sustaining its essential properties (Holling, 1973; Adger, 2000).

When a destabilizing new technology emerges, and taken-for-granted norms do not adapt consistently at the same speed, a decoupling process arises: on the one hand, norms as structural elements do not change, but on the other hand, a new emerging social system behavior emerges due to the interaction between an unchanged structural element of the [infV] (norms) and a new one (technology). In particular, in the last decades of the Anthropocene, the interaction between norms and technology seem to be more and more characterized by a stressing decoupling. Actually, in the current $21^{\text {st }}$ century, one of the main source of non-linear deviations is the endless emergence of new technologies (Harari, 2018; West, 2017). A compelling example of this systemic decoupling-recoupling interaction between new technologies and norms can be found in the field of environmental sustainability. Evolution of technologies and norms are strongly intertwined each other, so much so that it would be more appropriate to speak of coevolution. This coevolution, however, happens at a different speed.

On the one hand, the R\&D efforts give rise to better technologies (such as BATs, Best Available Technologies) that should imply a lower environmental impact and better protection of people's health. The coevolution of BATs should be taken into account to effectively improve environmental regulations (e.g. levels of risk of exposure to a toxic substance or reduction of the amount of waste in the landfill). On the other hand, however, environmental regulations recouple the novelty embedded in these evolutions with a temporal leg (Conti, 2018).

The increasing digitization of the world gives a second enlightening example. Digital technology has become the historical space of public communication. In the past, this role was played by specific physical spaces (streets, squares, churches). The digital space offers obvious advantages: groups can be organized without physically moving, costs are low, communications occur in real-time. In this sense, the web makes protest and participation possible. However, as underlined among others by the German sociologist Ulrich Beck (2016) and by the Israeli historian Yuval Noah Harari (2018), these digital spaces, like the related digital communication, are created and managed by transnational private market players. Therefore, the sovereignty of public debate is occupied by the power of private companies with the risk of a possible digital dictatorship. There is a dramatic tension: on the one hand, there is an increasing ask of public regulation of the web; on the other hand, the evolution of the web and the digital distributed technologies give rise to decoupling from the extant set of rules.

A third eloquent example is a technological innovation in reproductive medicine. Today, conception can be shaped by medical technology. This opens up to a new technical horizon that asks for a newly consistent set of rules: the available technologies can manufacture human life, but the set of rules still 
takes time to regulate these new revolutionary technical possibilities. Reproductive medicine creates new options [positive $\Delta i n f V$ ], and at the same time, it provokes a decoupling from the extant set of norms and the current language (meaning and significance). In front of this decoupling, we are asked to be resilient and we are forced to invent new words and norms to indicate and regulate new phenomena (re-coupling).

A fourth example is provided by the case of UBER in Italy: similarly to other cases such as Airbnb, the on-line world spills-over in the off-line world giving rise to a decoupling, unveiling a normative void and fueling socio-economic conflict related to the need to defend/attack economic income positions.

As suggested by the previous examples, the non-linear deviations triggered by a new technology innovation seem to accelerate in the emerging social systems characterized by the dual digital and biotechnological revolution. In this case, by adopting the lens of the VSA, it is possible to framing the issue not only in structural terms instead, and above all, according to a system way to think that leads to consider the interaction between the structural elements: the unchanged structural elements (norms) and the new structural one (new technology). By focusing on the interaction among the structural elements, the VSA leads to a deeper understanding of the decoupling-recoupling processes as expressions of the VS resistance-resilience capability.

The interactions between the new technology (source of unpredictability) and the taken-for-granted norms (source of predictability) affect the extant equilibrium among self-organization and command and control social mechanisms, which provokes a crisis and demands a social effort to be led (Barnard, 1938; Gouldner, 1954; Crozier, 1963, 1971; Barile et al., 2017; Simone et al., 2017), fueling in the meantime the risk of a social conflict.

Figure 1 tries to frame the endless interaction between new technology and norms in terms of decoupling-recoupling process. Starting from a satisficing norms-technology coupling in a certain time $\mathrm{t}(1)$, a new technology provokes a $\left[\Delta \inf V_{t}\right](2)$; this could trigger a decoupling process and then lead to a rethinking of the extant taken-for-granted norms. If norms resist (3), the technology will develop without involving a deep change in the most stable part of the [infV]. If the technology is destabilizing, it would be expected that the normative void will be filled by a new norm-driven recoupling involving a coevolutive change in the deeper part of the [infV] (4).

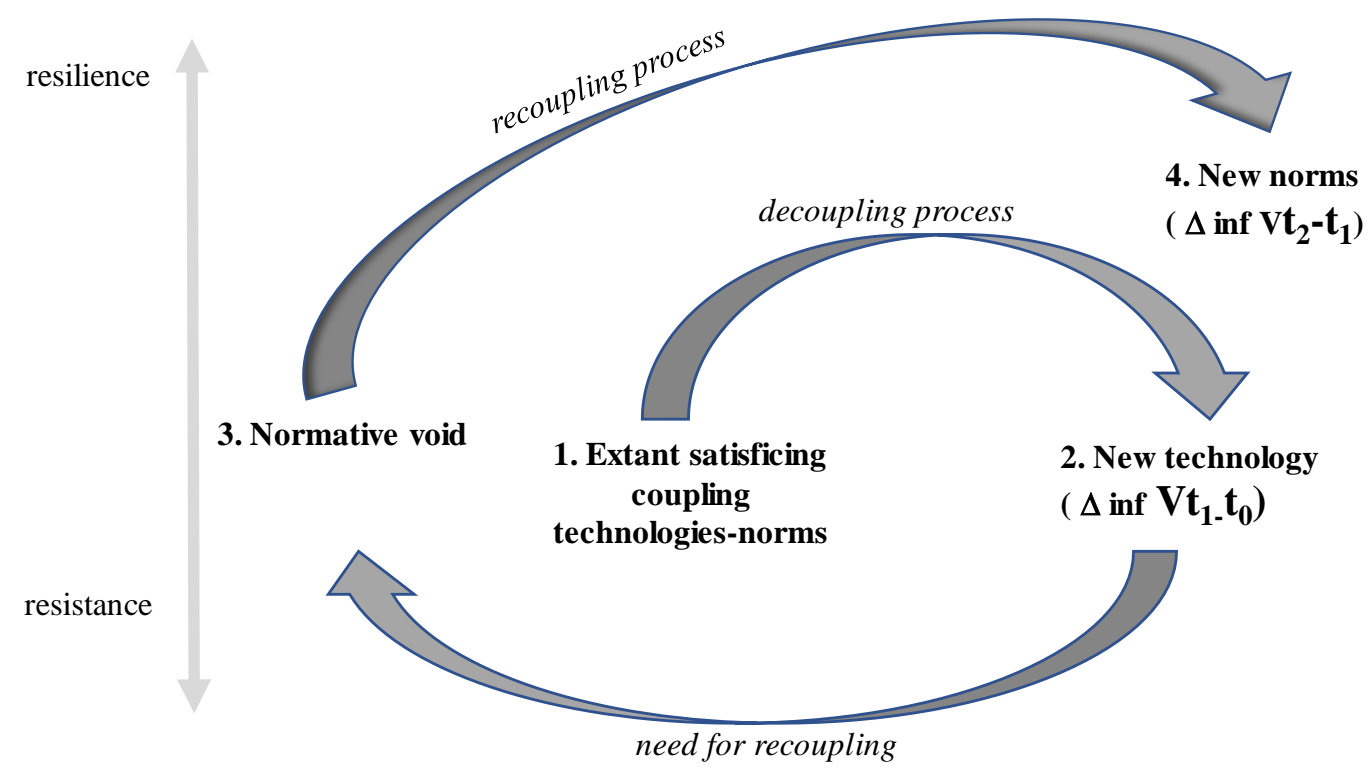

Fig. 1 - New technology and norms: the recursive decoupling-recoupling process; source: our elaboration 
For nearly half a century, social theorists have argued the virtues of decoupling and its importance for and social effectiveness. Decoupling enables societies to be resilient maintaining standardized, legitimated, formal structures while their activities vary in response to challenges and practical considerations (Bromley and Powell, 2012; Crilly et al., 2016; Meyer et al., 1983; Lawrence and Suddaby, 2006). Moreover, decoupling allows societies to ceremonially comply with their elements while engaging in activities that are necessary for their own wellbeing (e.g. Hirsch and Bermiss, 2009). In other words, when discussing the social system behavior, social theorists typically acclaim the virtues of decoupling processes for allowing resilience.

However, decoupling advantages could arise together with several problems of coordination, culture alignment and social identity (Kunda, 2009). When decoupling persists over time actors lose faith in the taken for granted norms because their allowed options do not match the reality of their available possibilities (Meyer and Rowan, 1977; Zbaracki, 1998; Diamond, 2012; Groleau et al., 2012). The result is social instability (Orton and Weick, 1990). This is particularly evident in the interaction between new technology and extant norms. From a conceptual standpoint, if norms do not reflect nor effectively discipline the exploitation of the new technology at people's disposal, two outcomes may occur: either people will stop viewing previous norms as natural and proper, growing unhappy (Barley and Kunda, 2001); or people will cease to care what society mandates and will pursue practices they believe help them to live better (Meyer et al., 1983; Covaleski and Dirsmith, 1983). In this case, therefore, decoupling could give rise to a loss of authority, order, legitimacy or effectiveness when the norms crumble and become inadequate (Covaleski and Dirsmith, 1983; Hirsch and Bermiss, 2009).

Whether decoupling is felt like a dramatic crisis or, on the contrary, as a discovering opportunity, to collapse in a resilient transformation, it needs a complementary recoupling process between the new technology and the taken-for-granted set of norms. Recoupling, as "the process of creating tight couplings where loose couplings were once in place" (Hallett, 2010), therefore, is the way by which social actors can reinstate a tightly coupled (namely, viable) system.

Decoupling new technology from norms, thus, is not necessarily a bad thing. Often, it is a healthy response to dealing with unknown and emerging problems since innovation evolves much faster than norms (Arthur, 2009). Resilient social systems decouple new technology from norms because this allows us to solve problems more quickly than the speed at which new norms are created. In so doing, new technology may trigger an emerging, non-linear decoupling process from the extant set of norms: individuals and organizations may begin to engage in practices that do not align with the taken-forgranted norms to live together.

According to non-linear processes, the technology-driven decoupling asks for a recoupling: a feedback process through which deviant behaviors and practices must be brought into alignment with existing norms or whereby old rules must be changed to fit the new organizational and social needs (Sauder and Espeland, 2009; Bromley and Powell, 2012; Dick, 2015).

\section{FINAL REMARKS: NEITHER RESISTANCE NOR RESILIENCE. THE RISK OF VULNERABILITY}

Rooting in the Viable System Approach (VSA), the paper has investigated how the dyadic relationship between technological innovation and norms act as an inhibitor (i.e. a source of resistance) or an amplifier of resilience.

The meaning of resilience - from the Latin resaltare, which means to rebound or bounce back, to get moving again, and possibly from resilire, with the literal meaning of to jump backwards - indicates the capability of adapting and changing in the face of unforeseen events. Every system naturally contains some degree of resilience that allows it to flex and adapt to counteract forces that would potentially drive it toward a dangerous brittleness (Gordon, 1978; Bodin and Wiman, 2004; Taleb, 2010). Accordingly, the essence of resilience is the intrinsic ability of complex systems (natural or social) to dynamically maintaining or regaining their own equilibrium, preserving their viability after a major mishap and in the presence of continuous stress (Hollnagel et al., 2006; Zolli and Healy, 2012). 
Differently from resilience, resistance is linked to the ability of a system to resist to damage remaining substantially unchanged until it breaks: it represents the systems' imperturbability to change (Bottrell, 2009). This does not necessarily mean that the system will remain as it was before the change or the impact of an unforeseen event, but that it will keep its essential functions substantially unchanged until it fails (Adger et al., 2006; Batty, 2013). Resistance does not ensure the systems access to alternative resources, nor the restoration of its structures, nor the recovery of its essential functions: if a system resists, it means merely that its resources were sufficient to withstand (Adger, 2006). However, a strategy that exclusively relies on resistance would certainly be very costly, potentially harmful and likely in conflict with social norms and individual freedom: when such a strategy fails the system becomes rigid (Thompson, 1967) and once broken, it is irreparable. Therefore, the more a system strengthens its boundaries to resist, the higher the risk that it becomes rigid, the greater it loses the capacity to absorb change, the greater is the speed with which this loss occurs in an endless feedback towards vulnerability.

This also provides the base for detecting the role of decision-makers and institutions in making a system vulnerable, resistant or resilient: i.e. the congenital nature of their [infV]. [InfV] is important for understanding the meaning and the impact of a black swan because it determines how the event is perceived and interpreted and which consequences it may have (Barile, 2008). This evidence is even more relevant in the current era of the Anthropocene where also human nature is experiencing its own boundaries becoming fuzzier and fuzzier, from the augmented human (Homo+) hypothesis to the posthuman hypothesis. Technology is one of the most relevant leavers through which this change is occurring. Consequently, these issues seem to dictate the end of consolidated models (mental, educational, strategic, organizational, cultural, social, etc.) and, at the same time, they ask for new "maps" enabling old and new actors to succeed - or at least to survive - in such innovation-shaped landscape.

However, how do societies react to these pressures? Despite its resilient nature and its relevance for modern societies, technology is not neutral. Accordingly, it is pivotal to consider its relationship with norms, source of security, certainty and social order.

In this direction, we contribute to the literature by introducing the concepts of decoupling and recoupling as tools to frame and understand this dynamic. Technological innovation makes possible what until yesterday was unthinkable, giving rise to the need of new socio-organizational structures and new norms. This provokes a decoupling from the extant set of norms and language: technological innovation asks for a new order, i.e. new consistent norms to recouple the change it brought (North, 2006). The outcome of this adjustment, however, is not given. In the presence of disruptive innovation, in fact, an eventual lack of readiness could result in a fall of social resilience and a consequent social collapse (Adger, 2006).

It is implausible that one could block or stop this high-risk/high-performance technologies diffusion. It is more feasible to think that as the risk of a social collapse grows more acute (think, for example, to the more and more concrete eventuality of an ecological collapse), investments in these technologies will dramatically increase. In such a scenario, systems vulnerability precisely lies in the total lack of recoupling between norms and technological innovation: this normative void would leave all the power in the hands of those who govern the process of the technological revolution. For example, who owns data? They are the most important strategic resource for governments, companies, institutions, they have replaced the role that land and physical resources had until the end of the twentieth century. Nevertheless, the dynamics of norms evolution seems to struggle in the face of the speed of technological change, letting a worrying normative void emerge (Fig. 2).

As showed in fig. 2 norms and technological innovation are persistently misaligned but profoundly intertwined: as long as they will be considered as separate and unrelated phenomena, policy makers will not be able to understand nor frame their interaction and deep social impact. Here is the relevance of systems thinking and VSA in particular: it allows to reflect on this social misalignment by highlighting both its structural and the systemic nature and stressing the always changing outcome, in a constant tension among resilience, resistance and vulnerability. 


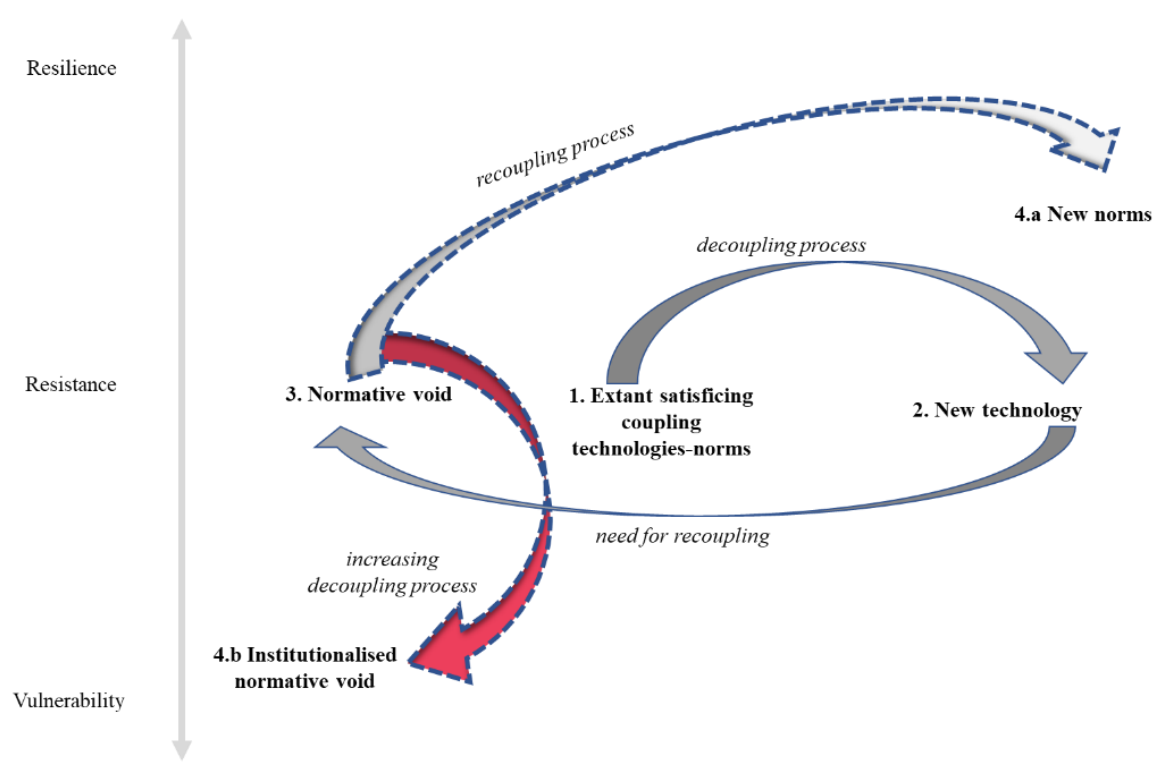

Fig. 2 - The interaction between new technology and norms: from resilience to vulnerability.

\section{REFERENCES}

Adger, W. N. (2006) Vulnerability. Global environmental change, 16(3), 268-281.

Adger, W.N. (2000) Social and ecological resilience; are they related? Progress in Human Geography, 24(3), 347-364.

Arthur, W. B. (2009) The nature of technology: What it is and how it evolves. Simon and Schuster.

Ashby,W.R. (1956) An Introduction to Cybernetics; Methuen: London, UK.

Ashby, W.R. (1958) Requisite variety and its implications for the control of complex systems. Cybernetica 1 (2), 83-89.

Barile, S. (2008) L'impresa come sistema: contributi sull'Approccio Sistemico Vitale (ASV). Giappichelli.

Barile, S. and Saviano, M. (2011a) Foundations of systems thinking: the structure-system paradigm”, Contributions to Theoretical and Practical Advances in Management - A Viable Systems Approach (VSA), International Printing, Avellino, 1-25.

Barile, S., Saviano, M. (2011b) Qualifying the concept of systems complexity. Various Authors, Contributions to Theoretical and Practical Advances in Management. A Viable Systems Approach (VSA). ASVSA, Associazione per La Ricerca sui Sistemi Vitali. International Printing, 27-60.

Barile, S., Simone, C., \& Calabrese, M. (2017) The economies (and diseconomies) of distributed technologies: The increasing tension among hierarchy and p2p. Kybernetes, 46(5), 767-785.

Barley, S. R., Kunda, G. (2001) Bringing work back in. Organization science, 12(1), 76-95.

Barnard, C. (1938) The Functions of the Executives, Harvard University Press, Cambridge, Mass.

Bateson, G. (1979) Mind and nature: A necessary unity (Vol. 255). New York: Bantam Books.

Bateson, G. (1972) Steps to an Ecology of Mind: Collected essays in anthropology. Psychiatry, Evolution, and Epistemology, 381.

Batty, M. (2013) Resilient cities, networks, and disruption.

Beck, U. (2016) The metamorphosis of the world, Polity Press, Cambridge, UK.

Beer, S. (1972) Brain of the Firm, The Penguin Press, London

Bodin, P., Wiman, B. (2004) Resilience and other stability concepts in ecology: Notes on their origin, validity, and usefulness. ESS bulletin, 2(2), 33-43. 
Bottrell, D. (2009) Understanding 'marginal' perspectives: Towards a social theory of resilience. Qualitative social work, 8(3), 321-339.

Bromley, P., Powell, W.W. (2012) From smoke and mirrors to walking the talk: Decoupling in the contemporary world, The Academy of Management Annuals, 6, 1, 483-530.

Conti, M. E., Tudino, M. B., Finoia, M. G., Simone, C., \& Stripeikis, J. (2019) Managing complexity of marine ecosystems: From the monitoring breakdown structure (MBS) to the baseline assessment. Trace metal concentrations in biomonitors of the Beagle Channel, Patagonia (2005-2012). Ecological Indicators, 104, 296-305.

Conti, M.E. (2018) Il management ambientale. Teorie, metodi e strumenti in una prospettiva sostenibile. Edizioni Nuova Cultura, Roma, pp. 480.

Covaleski, M. A., Dirsmith, M. W. (1983) Budgeting as a means for control and loose coupling. Accounting, Organizations and Society, 8(4), 323-340.

Crilly, D., Hansen, M., Zollo, M. (2016) The Grammar of Decoupling: A Cognitive- Linguistic Perspective on Firms' Sustainability Claims and Stakeholders' Interpretation. Academy of Management Journal, 59(2), 705-729.

Crozier, M. (1963) Le phenomene bureaucratique, Seuil, Paris.

Crozier, M. (1971) La societè bloquée, Seuil, Paris.

Diamond, J. (2012) Accountability policy, school organization, and classroom practice: Partial recoupling and educational opportunity. Education and Urban Society, 44(2), 151-182

Dick, P. (2015) From Rational Myth to Self-Fulfilling Prophecy? Understanding the Persistence of Means-ends Decoupling as a Consequence of the Latent Functions of Policy Enactment. Organization Studies, 36(7), pp. 897-924.

Elsbach, K.D. (2002) Intraorganizational Institutions. In J.A.C. Baum. Companion to Organizations. 37-57. Oxford, UK: Blackwell Publishers Ltd.

Espejo, R., \& Harnden, R. (1990) The viable system model. Systems practice, 3(3), 219-221.

Gordon, J.E. (1978) Structures. Penguin Books, Harmondsworth, UK.

Gouldner, A. (1954) Patterns of Industrial Bureaucracy, The Free Press New York.

Groleau, C., Demers, C., Lalancette, M., Barros, M. (2012) From hand drawings to computer visuals: confronting situated and institutionalized practices in an architecture firm. Organization Science, 23(3), 651-671.

Hallett, T. (2010) The myth incarnate recoupling processes, turmoil, and inhabited institutions in an urban elementary school. American Sociological Review, 75(1), 52-74.

Harari, Y. N. (2018) 21 Lessons for the 21st Century. Random House.

Harrison, G. W. (1979) Stability under environmental stress: resistance, resilience, persistence, and variability. The American Naturalist, 113(5), 659-669.

Hayek, F. A. (1952) The sensory order: An inquiry into the foundations of theoretical psychology. University of Chicago Press.

Hayek, F. A. (1979) Law, legislation and liberty: A new testament of the liberal principles of justice and political economy. University of Chicago Press.

Hirsch, P. M., \& Bermiss, Y. S. (2009) Institutional "dirty" work: preserving institutions through strategic decoupling. Institutional work: Actors and agency in institutional studies of organizations, 262.

Holling, C. S. (1973) Resilience and Stability of Ecological Systems. Annual Review of Ecology and Systematics, 4, 1-23.

Hollnagel, E., Woods D.D., Leveson, N. (eds.) (2006) Resilience Engineering. Concepts and Precepts, Farnham: Ashgate. 
Lake, P. S. (2013) Resistance, resilience and restoration. Ecological management \& restoration, 14(1), 20-24.

Lawrence, T. B., \& Suddaby, R. (2006) Institutions and institutional work. The SAGE Handbook of Organization Studies, 215.

March J. (1994) Primer on decision making: How decisions happen, Simon and Schuster.

Maturana, H.R.; Varela, F.J.; Beer, S. (1975) Autopoietic Systems: A Characterization of the Living Organization; Biological Computer Laboratory, University of Illinois: Champaign, IL, USA, 1975.

Meyer, J. W., Rowan, B. (1977) Institutionalized organizations: Formal structure as myth and ceremony. American journal of sociology, 340-363.

Meyer, J. W., Scott, W. R., Deal, T. E. (1983) Institutional and technical sources of organizational structure: Explaining the structure of educational organizations. In J. W. Meyer and W. R. Scott (Eds.), Organizational environments: Ritual and rationality: 45-67. Beverly Hills, CA: Sage.

North, D. C. (2006) Understanding the process of economic change. Academic foundation.

Sauder, M., Espeland, W.N. (2009) "The discipline of rankings: Tight coupling and organizational change", American Sociological Review, Vol. 74 No.1, pp. 63-82.

Simon, H.A. (1947) Administrative behavior: A study of decision-making processes in administrative organization. Macmillan.

Simone C., La Sala A., Montella M.M. (2017). The rise of P2P ecosystem: a service logics amplifier for value co-creation, The TQM Journal, 29, 6, 863-880.

Simone, C., Barile, S., \& Calabrese, M. (2018) Managing territory and its complexity: a decisionmaking model based on the viable system approach (VsA). Land Use Policy, 72, 493-502.

Stark, D. (2014) On resilience. Social sciences, 3(1), 60-70.

Taleb, N. N. (2010) Robustezza e fragilità. Che fare? Il cigno nero tre anni dopo. Il Saggiatore.

Van Maanen, J., Barley, S. R. (1984) Occupational communities: Culture and control in organizations. In B.M. Staw and L. L. Cummings (Eds.) Research in organizational behavior. Vol. 6. Greenwich, Connecticut: JAI Press.

Von Bertalanffy, L. (1968) General System Theory, Foundations, Development, Applications, George Braziller, New York, NY.

Von Foerster, H. (1984) Observing systems. Intersystems publications.

Watzlawick, P. (1984) The invented reality: Contributions to constructivism. NY: W. W Norton.

Watzlawick, P., Weakland, J.H. and Fisch, R. (1974) Change. La formazione e la soluzione dei problemi, Astrolabio, Roma.

West, G. B. (2017) Scale: the universal laws of growth, innovation, sustainability, and the pace of life in organisms, cities, economies, and companies. Penguin.

Zbaracki, M. J. (1998) The rhetoric and reality of total quality management. Administrative science quarterly, 602-636.

Zolli, A., \& Healy, A. M. (2012) Resilience: Why things bounce back. Hachette UK. 
